\title{
Nem melhor nem pior. Apenas uma escavação diferente
}

\author{
José Roberto Pellini*
}

\begin{abstract}
PELLINI, J.R. Nem melhor nem pior. Apenas uma escavação diferente. R. Museu Arq.
\end{abstract} Etn., São Paulo, n. 21, p. 3-15, 2011.

Resumo: As recentes críticas à metodologia de escavação têm enfatizado sua natureza hierárquica e a persistência de métodos objetivos de coleta de dados. Embora as atuais técnicas de escavação produzam inestimável informação sobre o material e sobre o sítio, elas pouco dizem muito sobre o passado propriamente dito. Neste sentido precisamos de um trabalho de campo mais reflexivo, criativo e intimista e não apenas um registro passivo de evidências. É neste cenário que foi realizada a escavação do sítio Cambaiuvas por uma equipe de alunos e professores do IGPA/PUC-GO sob a coordenação do Dr. José Roberto Pellini.

Palavras-chave: Teoria Arqueológica - Prática de campo - Pós-Processualismo.

\section{Inquietações}

"Eu fui à Floresta porque queria viver livre. Eu queria viver profundamente, e sugar a própria essência da vida... expurgar tudo o que não fosse vida; e não, ao morrer, descobrir que não havia vivido".

\section{Henry David Thoreau}

ão quase seis da tarde, o sol está se

$\checkmark$ pondo no horizonte deixando o céu avermelhado. $\mathrm{O}$ friozinho anuncia o fim dos trabalhos trazendo aquela sensação reconfortante de voltar para casa. Ando por entre as sondagens abertas fazendo algumas anotações. A cerca de 30 metros de onde estou a equipe está finalizando a última sondagem. São dois rapazes contratados na cidade vizinha e mais um técnico em arqueo-

${ }^{*}$ ) CULT Arqueologia. Coordenador Científico VI TAAS. <jrpellini@yahoo.com.br> logia. O papo está animado, para variar o tema é futebol. Me aproximo e observo as fichas. O que vejo são apenas algumas informações desconexas. Sigo adiante pensativo. Mãos doloridas, fichas sujas de terra, trinta sondagens realizadas e mais de quatro mil fragmentos de cerâmica quantificados em uma semana. O resgate está finalizado, as fichas de material estão prontas e organizadas, o material acondicionado, o discurso preparado. Mas e o passado? Será que após todo este trabalho chegamos mais perto do passado que procuramos entender? O que há de real nas cores que anotamos, nas medidas que tomamos dos perfis, nas camadas que separamos estratigraficamente, nos 10 em 10 centímetros convencionais que seguimos? O que isso realmente representa do passado? O que realmente achamos que estamos produzindo sobre o passado com tantas medidas, tantos dados, tanta padronização?

Pensemos juntos. Quando você quer comprar uma casa, o que faz? Lê atenciosamente a descrição do imóvel que o corretor lhe passou e se dá por contente ou vai até a casa, olha, 
verifica a estrutura, observa a rua, o entorno, caminha pelas dependências, testa as torneiras, analisa se a luz natural é boa, se o sol bate na janela da cozinha?

Façamos um pequeno exercício. Imagine um lugar no qual você vai com certa frequência. Pode ser a casa de um amigo muito próximo. Feche os olhos e tente se lembrar de tudo que há na sala de visitas. Difícil não é? Vamos tentar outro ambiente, seu quarto de dormir, por exemplo. Tente se lembrar de todos os objetos que há no quarto, tente se lembrar da disposição dos objetos e do porquê eles estão lá. Ficou mais fácil não ficou? Mas aposto que você se esqueceu da pantufa do Pernalonga que está perto da porta. Mesmo tendo grande intimidade com seu quarto, mesmo passando boa parte de sua vida nele, é natural que você tenha esquecido de algum pequeno detalhe. Agora imagine, se mal conseguimos lembrar e interpretar nosso próprio quarto, como queremos interpretar um sítio no qual passamos apenas quatro dias?

Creio que basta olharmos a complexidade de nosso dia a dia para percebermos que a arqueologia, como a praticamos, é contraditória. Pretendemos entender o passado, a vida das pessoas no passado e esquecemos completamente as lições e as experiências que vivemos no dia a dia. Esquecemos o básico. Esquecemos que nossas vidas não se resumem a uma série de números. Porque será que na vida valorizamos tanto a experiência e na ciência somos tão desapegados e distantes? Será que não estamos praticando ciência de uma maneira errada?

O passado é algo que já foi e entrar nele requer um pouco de imaginação. Na verdade, acredito que aquilo que podemos perceber, conhecer ou vivenciar em um sítio arqueológico ou na vida em geral depende não só da realidade com a qual lidamos, mas também de nossa percepção. Como diria Tilley (2004) o mundo real é o mundo percebido. Somos capazes de enxergar apenas as sombras projetadas por nós mesmos sobre o passado.

Cansado pelo longo dia de trabalho e assolado por dúvidas me recosto ao pé de uma árvore. Neste instante aproxima-se de mim um homem de barbas longas e grisalhas, pé no chão e olhar profundo. Diz ele:
- Você me pede Homem que fale de mim mesmo, dentro das estórias e histórias que escreverá...Vou lhe atender Homem, porque Você me chamou com os dois braços de abraçar, o Amor e a Poesia. Mas lhe direi poucas das coisas que fascinam seus irmãos, porque as águas de todos os rios vieram de tão longe e nelas as coisas aconteceram há tanto tempo que suas lembranças foram guardadas para ninguém. Outros, muitos outros Homens por mim passaram e nada me perguntaram tão cegos estavam por miragens além dos meus barrancos, que nem sequer me enxergavam. Alguns quiseram saber de tudo com detalhes.....A nenhum deles falei ou falarei. Mas falo a Você, Homem, e com quem pare para me olhar, para escutar os acordes regidos pelos ventos, para sentir o perfume sutil das sombras e por elas caminhar em cuidados de vigília, para pisar livremente em minhas praias, juntando as marcas de seus pés às pegadas dos animais e riscos das aves ribeirinhas e sobre eles dormir sob a noite de mistérios e de sons furtivos, noite de amantes.....quem quiser saber do que aconteceu, nos pergunte e a verdade, nossa verdade, será revelada..... (Borges 1987).

Sem dizer mais nada o homem se afasta e antes mesmo que eu pudesse ter tempo de pensar no que ele havia dito, vejo que outras pessoas se aproximam. São rostos conhecidos. Tilley, Hodder, Bender, Gavin Lucas, Sue Hamilton, Andrews, Bradley e outros. Levanto-me e vou até eles.

Tilley: Olá Pellini, viemos lhe fazer uma visita.

Pellini: Sejam bem vindos. Vocês aceitam um copo de chá?

Bender: Sem dúvida.

Lucas: Sabe Pellini, nos últimos anos tem crescido a crítica aos trabalhos de campo em Arqueologia. Como temos visto nos trabalhos de Lucas (2001), Hodder (2000), Tilley (2004) e Hamilton et al. (2006), parte dos trabalhos de campo que são desenvolvidos hoje em dia, segue uma postura bastante positivista.

Bradley: Concordo Lucas. As metodologias de campo estão cada vez mais padronizadas em função de cronogramas fechados e da necessidade de se adequar a orçamentos cada vez mais limitados, principalmente no que se refere à Arqueologia de Contrato. Tal situação tem levado a uma prática que vê o arqueólogo e os 
trabalhos de campo como meros fornecedores de dados (2003).

Whitmore: Assim como defendi em 2005, acredito que isso se dá porque em arqueologia a noção de trabalho de campo é convencionalmente contraposta ao contexto de produção de conhecimento. $\mathrm{O}$ trabalho de campo é visto como o lócus da coleta de dados enquanto o laboratório é visto como o lócus da produção de conhecimento. Hodder e Shanks já alertavam para isso em 1995. Em minha opinião, pouco mudou de lá para cá. Um reflexo disso é que o tema continua em voga.

Lucas: Mas Whitmore, devemos lembrar que ao mesmo tempo em que cresce a insatisfação diante das práticas tradicionais de campo, tem crescido também o desejo por práticas diferenciadas. Berggren e Hodder, por exemplo, propuseram metodologias reflexivas em 2003, Tilley em 1997 e 2004 e Cummings em 2002 propuseram o uso da fenomenologia. O que estes autores defendiam na realidade era um menor distanciamento entre os dados e a interpretação, maior integração entre os processos de escavação e pós-escavação e principalmente um maior envolvimento de outras vozes no processo de construção do conhecimento arqueológico (2001).

Bradley: Eu particularmente acredito que justamente porque a arqueologia não permite uma reprodução controlada dos processos de escavação, já que a escavação é em si um processo de transformação das evidências materiais, sendo difícil retornar a uma situação primeira, é que o momento da escavação deveria ser o momento de maior concentração de conhecimento, de vozes e de narrativas interpretativas. É neste momento que interpretações alternativas podem ser exploradas e uma grande gama de dados pode ser levada em conta (2003).

Berggren e Hodder: O problema Bradley, é que poucos veem que considerar o trabalho de campo apenas como uma técnica e dissociá-lo do processo intelectual resulta em uma arqueologia ruim da mesma maneira que separar a coleta de dados da interpretação resulta em um processo científico ruim. Escavar não é apenas uma técnica de julgamento, mas é a habilidade de lidar com um grupo quase infinito de in- formações e interpretações. Se considerarmos o registro arqueológico como um processo de catalogação e coleta de fragmentos materiais da atividade social, retiramos do processo de registro o componente humano responsável pela própria formação do registro (2003).

Edgeworth: Eu vou um pouco mais além Berggren. A presunção de que a arqueologia pode funcionar simplesmente como um procedimento descritivo e de registro nega a centralidade da pesquisa e remove a demanda interpretativa das construções narrativas. Enquanto as técnicas de escavação produzem inestimável e extensiva informação sobre o material e sobre o sítio, elas não dizem nada sobre o passado propriamente dito. $O$ passado não é apenas aquilo que é registrado, mas é aquilo que é produzido através da documentação arqueológica, das práticas de escrever, fotografar, registrar. Acredito que o registro arqueológico é composto não apenas pela cultura material pretérita, mas também do registro documental que se faz desta cultura material (2003).

Pellini: Ou seja, podemos presumir então que, quando criamos teorias sobre o passado, nossas interpretações partem na realidade não apenas da materialidade do sítio, mas da materialidade do texto.

Edgeworth: No momento em que um objeto é desenterrado, o arqueólogo traz à mente, a partir de sua experiência perceptiva, uma série de analogias que o auxiliam no processo de interpretação da evidência material. Neste sentido não somente a descoberta, mas todo o processo de escavação em si, são aspectos que carregam uma carga interpretativa importante, mas que é deixada de lado na análise arqueológica. No momento da descoberta, resgatamos a percepção dos esquemas ou racionalidades que temos do mundo material. Sendo assim nossas experiências passadas estão sempre presentes (2003). A natureza ativa das analogias e dos processos perceptivos é evidente mesmo nas tarefas mais simples e rotineiras do processo de escavação. Em um senso mais geral, os objetos são descobertos porque são observados e porque eles são reconhecidos nos termos de algum esquema conceitual pré-existente. Toda observação envolve interpretação simplesmente 
porque observações se tornam compreensíveis quando elas confrontam as expectativas prévias dos observados. Ao mesmo tempo estes esquemas são reforçados pela descoberta dos objetos. No fim, acredito que o ato de descobrir forma e reproduz um dado conhecimento (1992).

Pellini: Ou seja, podemos pensar então que nosso conceito do que é uma ponta de flecha consiste em muito mais do que uma imagem mental das formas e propriedades materiais do objeto. Todo o conhecimento ao redor do objeto não só está tacitamente presente no momento da descoberta como ele preexiste ao momento da descoberta.

Edgeworth: A ponta de flecha é um objeto conceitual do conhecimento arqueológico sendo que quando ele é descoberto ele retorna como símbolo material. Este conhecimento evoca imagens não somente do objeto em si, mas de toda a cadeia operatória envolta na sua produção desde a obtenção da matéria prima até sua utilização e descarte. Neste sentido sempre percebemos um artefato por referência a nós mesmos (1992).

Hodder: É justamente por isso que podemos dizer que no ato da descoberta os artefatos são reapropriados e cognitivamente remodelados de acordo com nossos esquemas e racionalidades, pois partimos de nossa percepção e dos conceitos difundidos pela comunidade arqueológica. Os artefatos assumem formas a partir da forma que damos a eles. $\mathrm{O}$ ato de descobrir pode ser definido como nosso contato original com uma entidade material. Todos os eventos subsequentes, sejam eles discursivos ou analíticos, são efetivamente dependentes do momento prático da descoberta. O grande problema é que normalmente este momento é tido apenas como a recuperação de evidências materiais, um processo no qual os agentes da descoberta são vistos apenas como agentes passivos (1999). Inclusive acredito que podemos falar de contexto arqueológico como a reunião não somente das evidências materiais em um sítio, mas também como as concepções dos arqueólogos, as perguntas formuladas e a interpretação proposta. Tal contexto está sempre mudando. Contexto assim não é somente o artefato e sua relação com a estratigrafia, a relação da estratigrafia com o sítio e a relação do sítio com o entorno, mas é um conjunto de concepções e interpretações que se manifesta a partir da relação dialética entre o arqueólogo e o objeto. $\mathrm{O}$ contexto neste cenário está sempre mudando em função de como ele é estruturado a partir dos códigos da própria disciplina arqueológica (2000).

Tilley: É por isso que acredito que a construção do passado deva ser abordada a partir de três materialidades distintas, mas entrelaçadas: a materialidade do passado, ou seja, a realidade física dos objetos; a materialidade do presente, a partir de onde o conhecimento sobre o passado é produzido pelo arqueólogo; e por fim a materialidade do processo que é a criação do discurso sobre o passado (1990). A arqueologia enquanto uma prática interpretativa que constrói socialmente e de forma ativa o passado no presente não é um mero reflexo passivo das coisas que ocorreram em tempos remotos. Passado e presente não são concebidos de forma oposta já que um se constitui em relação ao outro em um processo ativo de reciprocidade. Em arqueologia não há descrição pura, livre de interpretação uma vez que descrever, pensar e escrever é interpretar (2004).

Pellini: Masini (1991), por exemplo, ressalta que a neutralidade científica é intenção apenas oculta ou alienada, caso se insista em afirmá-la neutra. A neutralidade cientifica limita-se aos cuidados técnicos e metodológicos de não interferência nos resultados. Neste sentido a objetividade é constituída via subjetividade.

Bender: Creio que devemos ir além das evidências de campo, já que as evidências não proporcionam em si um entendimento direto do passado. Por exemplo, mapear um sítio não deveria ser uma planificação banal ou o registro das estruturas existentes. Ao contrário, o visitador deveria colocar o passado em uma experiência fenomenológica de "estar presente", criando assim um mapa mais profundo e completo. Aos arqueólogos não é permitido um salto imaginativo que é tão necessário para entender como as populações do passado poderiam ter conceitualizado sua relação com seu próprio espaço (1998).

Bradley: Sítios, paisagens e monumentos só podem ser interpretados a partir de uma 
longa exposição à evidencia de campo, pois é através da familiaridade com os vestígios é que podemos reconhecer todas as características salientes (2003). Na prática, a experiência da escavação deveria ser cumulativa. O problema é que a atividade de campo é rápida, principalmente na arqueologia de contrato como escreveu Chadwick em 2010. Mas quem pode se dar ao luxo de passar meses em um campo? Quem pode voltar ao sítio em diferentes estações ano após ano? Será que a luminosidade do espaço é igual em todas as estações? Será que o espaço é o mesmo de dia e de noite? Estamos em um abrigo, certo? Pois bem, como saber algo deste abrigo se, por exemplo, não o experimentamos debaixo de uma chuva torrencial? Será que na chuva ele nos revelaria seus segredos? A pressa em cumprir os cronogramas faz com que muitas das características do sítio e da paisagem não sejam observadas. Acho que é a partir da ideia de vivência que podemos começar a pensar em uma atividade de campo diferente da que está posta (2006).

Tilley: Acredito firmemente na ideia da vivência como o caminho para mudarmos nossa prática de campo. Mas acho também que não adianta apenas vivenciarmos o sítio, a paisagem se não mudarmos nossa estrutura narrativa. Os traços imateriais do passado são aspectos difíceis de abordar em um texto e talvez por isso sejam deixados de lado dentro das narrativas arqueológicas 2004.

Trigham: Acredito que o ato de escrever imaginativamente permite ao arqueólogo quebrar a rigidez do discurso oficial estabelecido e explorar o passado de formas diferentes (1991 e 1994).

Pellini: Tilley, acho que o ponto central é que a linguagem é um sistema limitado. Não raro, temos grande dificuldade de retratar toda a intensidade da experiência vivenciada. Faltam-nos palavras. Pensemos na paixão por exemplo. Será que a palavra paixão exprime realmente aquela ardência no estômago, a ansiedade, a pulsação acelerada.......estão vendo nem consigo definir exatamente aquele sentimento que temos quando estamos apaixonados. É por isso que acredito no uso de estruturas de linguagem mais criativas, pois o engajamento criativo com a linguagem permite uma narrativa evocativa antes que apenas descritiva.

Tilley: A linguagem poética, por exemplo, é cheia de metáforas e conjunções sensoriais que podem servir de analogias que auxiliam na descrição da experiência sensorial vivenciada. A escrita evocativa encorpa, traz as texturas da experiência vivida, estrutura em palavras nossos sensos com os sensos do mundo. A escrita encorpada é uma prática que aproxima o leitor das experiências de mundo do escritor (2004).

Pellini: Acredito que o que é mais importante em um texto não é o que ele significa, mas o que ele te incita a fazer. E como ele nos incita? Através das emoções que ele contém e transmite. E o que ele te incita a fazer? É preciso que sobre o real, supostamente objetivo, lancemos um olhar, transformando-o, denunciando-lhe o traço mágico, o fantástico, o maravilhoso. Para mim isso é fazer arqueologia. Talvez o caminho para a arqueologia que procuramos seja unir a vivência, novas estruturas narrativas, novas vozes, menos hierarquia. Mais fantasia.

Tilley: Concordo. A conversa está boa, mas o sol já se pôs, temos de ir embora. Vamos descansar e recomeçamos amanhã. Antes de irmos Pellini, gostaria de agradecer em meu nome e em nome dos meus colegas pelo convite para esta escavação. Viemos muito pouco ao Cerrado Brasileiro nestes últimos anos. Eu particularmente gostaria de ver com mais frequência este lindo pôr do sol, mas são poucos os convites.

- Não precisa agradecer Tilley, na realidade eu é que agradeço à presença de vocês aqui. Sintam-se sempre convidados.

Acordo sobressaltado. Parece que adormeci. Procuro pelo senhor de barbas grisalhas e não encontro. Procuro Tilley e os outros e não acho. Teria sido um sonho? Não sei ao certo, sei apenas que uma palavra ecoava em minha mente, vivência.

\section{Sonhos de intimidade}

A lua desponta na parte superior do Abrigo envolta em um manto filigranado de estrelas. A brisa sopra gelada, mas o ar está denso e carregado com sinais de mudança. O crepitar 
das chamas da fogueira dá inicio à celebração. Os convidados vão chegando de várias partes. Aquela seria uma noite de celebrações, descobertas e revelações. Aos poucos as pessoas vão se soltando e as conversas acaloradas se misturam com as risadas. Um casal procura a quietude da escuridão enquanto um grupo, sentado sobre a pedra discute sobre as vicissitudes da vida. $\mathrm{O}$ rio se torna o local de purificação e oferendas. A festa une os diferentes grupos e os copos de cerveja, ainda quente, ajudam a alterar o estado de consciência. Visto de longe o fundo do abrigo se torna vermelho com o reflexo das chamas da grande fogueira. Imagens se formam nas paredes e as sombras ganham vida. Parecem pinturas dançando ao som das vozes. O cheiro adocicado da carne assada embriaga a mente. $\mathrm{O}$ espaço se transforma. $\mathrm{O}$ rio, as árvores, as pedras no chão, não são mais seres indistintos, mas partes de um cenário sagrado. A ponte de madeira sobre o rio é o limite entre a fantasia e a realidade. Todo o entorno ganha vida, somos agora parte da paisagem.

Foi assim que vi encerrar-se o último dia de escavação no Abrigo Cambaiuvas, na cidade de Unaí em Minas Gerais. Os trabalhos de campo fizeram parte das atividades associadas à disciplina que eu ministrava no IGPA/PUC-GO em 2009. Participaram do campo além de mim, sete alunos do curso de graduação em arqueologia: Ricardo dos Prazeres, Diego Mendes, Jamaria Batista, Samara Dyva, Nayara Lopez, João Moreno e Caroline Murta, a Carol. A proposta básica do campo era tentar vivenciar o sítio, transformá-lo em nossa casa. Ele deixaria de ser um sítio arqueológico, um local "sagrado", para se tornar um lugar mais íntimo.

A ideia do campo nasceu após ver algumas crianças brincando em uma caixa de areia. Era uma atividade patrocinada pelo IGPA durante a Semana de Cidadania da PUC-GO. A fim de mostrar um pouco dos trabalhos da Arqueologia às crianças com idade de cinco a dez anos, caixas de areia foram montadas e réplicas de materiais arqueológicos enterrados. Cabia às crianças procurar os objetos e sob a supervisão de monitores, analisá-los. O que mais me chamou atenção era a maneira compenetrada com que os pequeninos se lançavam à atividade. Estavam envolvidos de corpo e alma. Era latente que estavam se divertindo. Seus olhares transpareciam alegria, diversão e uma curiosidade ingênua. É incrivel como caixas de areia e crianças se completam tão bem. Pensei comigo, é isso que está faltando. Precisamos nos fundir ao sítio, à paisagem, a ponto de não mais sabermos quem somos. O sítio deveria se tornar nossa caixa de areia. Seria muito fácil, eu como coordenador, determinar, fulano faça isso, sicrano faça aquilo. Depois de 15 dias iríamos embora e este seria só mais um sítio na vida de cada um dos participantes. Duvido que alguém, depois de três meses se lembraria desta escavação. Seria mais um sítio com listas intermináveis de sondagens, perfis estratigráficos mal traçados, catálogos de artefatos, enfim, um material que sobre o qual provavelmente ninguém mais iria se debruçar. Assim o sítio estaria perdido. Vocês já ouviram falar que quando você deixa de pensar em um brinquedo ele morre? Pois bem, se deixarmos de pensar no sítio ele também morre, ele desaparece. Para mim, resgatar um sítio não é simplesmente escavar e coletar material. Resgatar um sítio é lembrar-se dele. Acredito que o caminho para o conhecimento parta desta relação intimista com o local e era isto que estávamos procurando.

Mas como alcançar toda essa intimidade com o local? Creio que o primeiro passo seja desacelerar. Enquanto na cidade somos escravos do tempo, dos compromissos agendados, aqui, no meio do mato, o tempo passa devagar, lento, arrastado. A adaptação não é fácil, a perna fica agitada e o coração custa um pouco a desacelerar. Pode parecer uma questão menor, mas para mim este é um dos pontos centrais dos trabalhos de campo, pois ao impormos em campo o ritmo ditado pelo relógio, somos impedidos de adentrar na temporalidade do lugar. Não nos conectamos ao lugar e continuamos a ver o sítio e a paisagem como algo distante, dissociado de nós mesmos. Nunca levo relógio para campo justamente por isso. Como quando tenho fome, durmo quando tenho sono. Porque devemos imprimir um ritmo "urbano" em nossos trabalhos de campo? Porque temos de cumprir horário como se fôssemos uma agência bancária? Costume? Praticidade? Será que se tentássemos seguir 
um ritmo, digamos, diferente, fora dos padrões a que estamos acostumados em nosso dia a dia, não teríamos mais conectividade com o lugar? É por isso que acredito que nossa primeira tarefa em campo seja entrar no ritmo da paisagem, esquecermos quem somos e relaxar. Devemos esquecer as loucuras do cotidiano e mergulhar na quietude. Devemos aprender a respirar no ritmo do sítio, no ritmo do lugar e da paisagem. Por isso nossa primeira atividade foi simplesmente relaxar e buscar o ritmo do lugar. Durante dois dias todos estavam livres para andar pela mata, dormir ao pé das árvores, nadar no rio, enfim se acostumar com o lugar, a única cobrança era que escrevessem em seus diários de campo as sensações que tinham ao longo do dia.

Se no primeiro dia todos pareciam ainda muito agitados, no segundo dia já mostravam maior familiaridade com o espaço e pareciam mais relaxados. Esta primeira experiência foi tratada pelos alunos de maneira inusitada. Jamaria por exemplo disse: "Foi estranho chegar ao sítio e não começarmos a escavar. Passei parte do primeiro dia sem saber direito o que fazer". Ricardo foi outro que mostrou certa estranheza: "Primeiro fiquei andando aleatoriamente, procurando o que fazer, só depois de um tempo é que comecei a me acostumar com o local. Ficar livre o dia inteiro dá a impressão de que não estamos trabalhando". Samara, por outro lado, ressaltou a configuração do entorno: "A maneira como o rio parece estar diretamente associado ao abrigo me chamou atenção. Não é só uma questão de proximidade. É difícil explicar. Evidente que o rio deve ter desempenhado um papel importante enquanto fonte de água e alimento. Mas existem outros nichos na mata onde o rio passa e que aparentemente não foram ocupados. Mesmo este Abrigo não é a área mais abrigada do entorno. Aqui o rio parece estar em simbiose com o Abrigo. Mas não sei explicar exatamente o porquê. Eu particularmente tive a impressão que ao cruzarmos o rio, a mata nos traz diretamente para este ponto." Carol e alguns outros membros da equipe tiveram impressão parecida, o que não é de se estranhar desde que o caminho que usamos para chegar ao sítio havia sido criado dias antes de nossa chegada. Mas foi interessante notar como isso determinou parte da nossa percepção do sítio e da ambiência. No dia seguinte mudamos de caminho.

Uma das propostas da escavação era justamente dar asas a intuições como estas, que embora careçam de maior evidência empírica podem, em minha opinião, nos aproximar de diferentes significados do lugar. Boa parte da ciência que praticamos é baseada em fatos, em dados. Mas estou convencido cada vez mais de que a realidade que nos cerca é frágil, se é que realmente existe. Se pensarmos que nossa capacidade auditiva, limita-se a faixas entre 20 e 80 hertz, pergunto a vocês: o que escutamos realmente do som que um instrumento produz? Se pensarmos que vemos apenas determinadas faixas do espectro de luz, pergunto a vocês: o que realmente vemos quando olhamos o paredão do abrigo? $\mathrm{O}$ abrigo ou apenas parte dele? Não vemos, não tocamos, não sentimos a realidade física em sua forma completa. A realidade é apenas o que podemos experimentar da realidade, ou o que estamos preparados para experimentar. Ao mesmo tempo, não é a materialidade existir ou não, ou como ela existe no mundo o que importa, mas a maneira pela qual o conhecimento acontece, o ato pelo qual a pessoa apreende imediatamente o conhecimento de alguma coisa. Cores, cheiros, gosto, como eles ocorrem na percepção não são propriedades intrínsecas dos objetos que percebemos, mas construções culturais. Toda a informação sensorial é em si uma informação indireta sobre o objeto. Nosso corpo é um organismo limitado. Não podemos voar, não podemos andar debaixo d'água, não conseguimos ver as ondas infravermelhas, ou seja, nosso corpo prescreve os tipos de experiência perceptiva e os processos cognitivos que são disponíveis a ele. A forma geral do corpo influencia diretamente em como ele vai realizar as ações comportamentais e como ele irá perceber o mundo. Assim, um organismo com olhos irá experimentar o mundo de uma maneira diferente de um organismo desprovido de visão, um organismo sem pernas irá perceber e experimentar o mundo de maneira diferente do que um organismo com pernas. A nossa imagem mental do mundo só vagamente tem por base a realidade. 
Classen (1993, 1997) e Howes (1991, 2006) defendem, a partir de estudos etnográficos, históricos e antropológicos, que a percepção sensorial é uma construção cultural, ou seja, os significados que os indivíduos atribuem para os aspectos sensoriais são baseados nos modelos sensoriais adotados socialmente. Sendo assim, cada cultura concebe os sentidos de maneira diferenciada estabelecendo suas próprias hierarquias sensoriais (Howes 2006). Neste sentido, o entendimento sensorial do mundo não é apenas um aspecto fisiológico, mas é culturalmente determinado. Os grupos humanos reconhecem o aparato sensorial de acordo com seu próprio contexto, criando e mudando sentidos, criando e alterando hierarquias sensoriais. Nós aprendemos a ver, ouvir, sentir. Nós aprendemos a observar e não observar.

Mas o que isso tem a ver com as práticas de campo, com as metodologias de escavação?

Vejam, creio que o problema esteja no fato de que nossos hábitos como pesquisadores ainda estão demasiadamente enraizados nos paradigmas que sustentam a observação e a descrição como métodos objetivos e científicos. Dubord (1995) descreve a emergência do mundo da razão como um espetáculo em que a experiência foi substituída pela observação. Mas será que a observação pode substituir realmente por completo a vivência na formação do nosso conhecimento? Pergunto a você, monumentos, casas, construções eram criadas para serem experimentadas ou descritas? Artefatos eram feitos para serem manuseados ou para serem medidos e tabulados? Por mais que pareça óbvia esta constatação, me pergunto: por que então continuamos a apenas descrever nossos objetos de pesquisa? Talvez porque como arqueólogos, tenhamos nos acostumado a registrar e interpretar sítios e artefatos de modo muito visual, afinal, desenhamos perfis, tiramos fotos, lemos e escrevemos relatórios, realizamos descrições detalhadas de objetos e sítios. Nossa ciência é demasiadamente visual. Não só nossa ciência, toda a sociedade ocidental se tornou demasiadamente visual após o século XVIII. No Ocidente compreendemos e nos relacionamos com o mundo a partir da visão. Aprendemos pela visão. Mas será que as sociedades do passado também tinham a visão como seu senso princi- pal? Se não, e eu acredito que não, precisamos de técnicas e métodos diferenciados para alcançar a real significância do passado. Lembremos que o comportamento das pessoas é baseado na interpretação que fazem da realidade e não na realidade em si. Pela percepção formam-se imagens que têm significados diferentes para quem as capta, dependendo de sua cultura, tempo histórico, situação psicológica, emocional etc.. Acho que abordagens objetivas cumprem seu papel e são necessárias. Mas acho que precisamos agregar novos métodos e técnicas principalmente no que se refere às experiências perceptivas. Considerar os aspectos da vivência pode nos trazer insights interessantes a respeito de como as sociedades viviam no passado.

Evidentemente que muitos empreendedores ficariam insatisfeitos com pesquisadores dormindo em campo, nadando no rio, como bem salientou Ricardo ao longo de nossas discussões. Afinal poderíamos estar escavando e adiantando o cronograma. Sim, claro que poderíamos. Mas perderíamos a oportunidade de compreender melhor o local de implantação do sítio. Ganhamos um conhecimento que a sondagem não pode nos dar, um conhecimento que poderia permanecer escondido caso não prestássemos atenção no entorno. Começamos a vivenciar o local. Como diria Chesterton (1908-2008: 34) “[...] se olharmos 999 vezes para alguma coisa estaremos seguros, mas se olharmos 1000 vezes corremos o perigo de estar olhando para esta coisa pela primeira vez". Creio que seja esse o princípio de tudo. Intimidade. A intimidade revela detalhes que vêm apenas com o tempo, com o convívio. Devemos pensar em nosso trabalho em campo como um relacionamento amoroso. Alguém ousa dizer que conhece seu parceiro depois de uma semana? Claro que não!

Ao longo dos dias seguintes, reuniões eram realizadas todo o momento em campo a fim de discutir o andamento dos trabalhos e principalmente a eficácia dos métodos escolhidos. Temas como a espacialidade do abrigo, a paisagem de ocupação, os métodos reflexivos de escavação eram abordados todo o tempo. As decisões a respeito da escavação não eram verticalizadas, ou seja, toda a equipe tinha voz na escolha das estratégias de campo. Embora isso gerasse um 
custo tempo, principalmente diante de assuntos polêmicos como a escavação de uma estrutura de combustão, essa iniciativa permitiu a troca de informações e uma abordagem mais interpretativa em alguns momentos.

Um dos aspectos mais interessantes da escavação foi quando o time, em uma das reuniões, observou que a percepção espacial do grupo havia mudado. No primeiro dia de visitação a reação, quase que unânime, foi de que o abrigo era pequeno demais para suportar uma ocupação de longa duração ou mesmo um grupo grande de ocupantes. Em virtude desta primeira impressão uma das hipóteses levantadas era de que o abrigo teria funcionado como acampamento sazonal para a coleta de recursos ambientais ligados à subsistência e coleta de matéria prima. Com o passar dos dias o grupo foi se acostumando com o ambiente e naturalmente se adequando à espacialidade do abrigo. Sem uma pré-determinação, áreas para a alimentação e descanso foram criadas, áreas de caminhamento foram definidas e o time, que chegou a contar com quase 20 pessoas, conviveu harmoniosamente em um espaço que, como havia definido Jamaria, "não era capaz de abrigar mais que cinco pessoas".

Essa mudança de perspectiva espacial fez com que o time de escavação questionasse a própria delimitação do sítio. Pode-se perceber que o sítio não era delimitado pela materialidade dos vestígios arqueológicos. A constatação, como expressou Carol, era simples: "se estamos utilizando tanto a porção lateral do abrigo, quanto a área frontal, porque não considerar que aqueles que viviam aqui, utilizavam uma área até maior? Nós, por exemplo, utilizamos a parte da frente para dormir depois do almoço. Quase nenhum traço ou vestígio material faz referência a esta atividade, mas mesmo assim esta porção da paisagem está diretamente conectada ao nosso espaço de vivência. Será então que o sítio deve ser delimitado apenas pelos locais onde verificamos a presença de vestígios materiais?" A constatação de que um sítio arqueológico possui uma área útil que ultrapassa o local onde se identificam restos materiais, fez com que as próprias estratégias de escavação fossem rediscutidas. Neste sentido buscamos outras formas de delimitar o sítio, usando o tato do abrigo, os sons, o cheiro, a luminosidade do ambiente etc..
Entre as diversas atividades que foram performadas no sentido de criar uma maior vivência da paisagem e do Abrigo se destacaram as atividades de coleta de matéria prima e lascamento. Diego e Ricardo, os mais interessados em material lítico formaram uma equipe de prospecção com o objetivo de mapear as áreas de captação de recursos e coletar matéria prima para um lascamento experimental. $\mathrm{O}$ time de prospecção decidiu, com o consenso de todos, paralisar suas atividades no sítio e sair durante alguns dias logo pela manhã em busca de rochas propícias para o lascamento. Em geral caminhavam a manhã toda, nem sempre com resultados positivos. Após dois dias sem grandes resultados, Diego sugeriu que a área de captação de recursos provavelmente seria mais afastada do sítio e as atividades de lascamento envolveriam o transporte de núcleos semi preparados para o lascamento.

Com as poucas rochas coletadas foi organizada uma atividade de lascamento experimental no sítio. Para tanto a equipe decidiu selecionar uma área em frente ao sítio, que foi limpa e quadriculada. O objetivo era comparar a dispersão dos restos de debitagem experimental com a dispersão espacial dos vestígios de lascamento presentes no abrigo.

Diego conduziu as ações, ensinando os mais novos como selecionar e debitar as rochas para se conseguir instrumentos. Ao longo da atividade, muitas brincadeiras, histórias e chistes foram feitos. Além de transmitir um conhecimento específico a atividade claramente aumentou a coesão social do grupo. Ao final a área delimitada para a atividade foi fotografada para registrar de maneira geral o posicionamento do material e recoberta com sedimentos para escavação posterior. Segundo o grupo, a ideia de recobrir a área com sedimentos visava permitir o livre caminhar sobre o local e assim simular alguns dos processos pós-depocicionais verificados em áreas do sítio.

Em consonância com as atividades de vivência foi realizada a coleta de dados de maneira mais tradicional. A diferença é que os dados eram produzidos em tempo real com o objetivo de municiar o time de escavação com o panorama total do que estava sendo observado no sítio. Sendo assim, análises de solo, com a determinação de índices de Nitrato, Fósforo e 
Potássio além do PH de cada estrato do sítio eram repassadas com a informação da quantidade de material no estrato, textura e coloração do solo. A cada alteração abrupta dos índices gerais, reuniões eram efetuadas para interpretar os resultados e guiar as novas abordagens.

Dentre todas as atividades realizadas, a que mais causou impacto, principalmente do ponto de vista emocional, foi a festa de confraternização realizada no abrigo na última semana de trabalho. A ideia nasceu de uma simples constatação: se estamos defendendo tanto a ideia de vivência, porque não passar um tempo no Abrigo à noite? Como diriam Carol, João e Diego, quase nunca levamos em consideração o aspecto noturno dos sítios e das paisagens em nossas interpretações. E sabem por quê? Simplesmente porque nunca estamos nos sítios neste horário. Para mim o fato de a atividade arqueológica ser prioritariamente uma atividade que se desenvolve de dia cria um quadro interpretativo em nossas mentes que desconsidera todas as possíveis atividades que foram possivelmente performadas durante a noite. Mas quem tem tempo de passar uma, duas, três noites em um abrigo em uma etapa de campo que tem dia e hora para terminar?

No dia da festa os membros do time foram convidados a passar o dia no abrigo escrevendo sobre o trabalho de campo, suas interpretações acerca da ocupação, se divertindo no rio ou realizando quaisquer atividades que pudessem contribuir para a interpretação do sítio. Por volta das seis da tarde com o sol já se pondo no horizonte, uma fogueira foi acesa e em volta dela foi criada uma área para assar carne. O céu e as imagens formadas pela sombra da fogueira no paredão do abrigo impressionaram os membros da equipe de escavação. Se o abrigo era branco de dia, com uma luminosidade ofuscante, de noite à sombra da crepitante fogueira ele se tornava vermelho. As sombras das pessoas em volta da fogueira formavam imagens na parede do Abrigo lembrando imagens rupestres vivas, algo que foi percebido por quase todo o grupo (Ricardo, Diego, João, Carol, Samara, Eu). Todos em algum momento comentaram o fato. Se estas imagens nos impressionaram, não teriam impressionado e motivado também aqueles que ali viveram?
Sei claramente que nenhuma das descobertas que fizemos é revolucionária. Sabemos que a espacialidade de um lugar muda com o tempo, com a vivência, com a idade, com o sexo etc. Sabemos também que atividades noturnas em sítios não são em si grande novidade, principalmente para aqueles que trabalham com registros rupestres. Saber que imagens "dançantes" podem ter influenciado aqueles que viveram no abrigo tampouco é muito singular. Ao mesmo tempo atividades de lascamento em campo, coleta de matéria prima, são atividades bem fundamentadas na Arqueologia Experimental. O diferencial aqui foi a maneira pela qual experimentamos o espaço. Pudemos ao longo dos dias, sentir a paisagem que nos cercava através de práticas cotidianas pouco usuais em trabalhos de Arqueologia de Contrato. Pudemos mergulhar na ambiência. A cada dia nos sentíamos mais habituados com o sítio, mais familiarizados com o lugar. Esse é para mim um aspecto chave, talvez o mais relevante da prática arqueológica, seja em campo seja no laboratório. $\mathrm{O}$ tempo reduzido imposto pela prática do Contrato nos tira a possibilidade de interagirmos mais intensamente com a paisagem. Quando Mário Quintanilha (1979) foi convidado por um amigo a conhecer a paisagem carioca, disse ele: "O que pensa que vou fazer meu caro amigo, dizer muito prazer em conhecê-la, minha senhora! Esse não pode ser um conhecimento voluntário, aprazado, mas uma lenta osmose inconsciente, de modo que no fim se fique pertencendo à paisagem, e vice-versa. Não se pode conhecer nada num minuto e só por isso é que os turistas não conhecem o mundo".

Em geral, em nossa prática não nos envolvemos. Deixamos de fazer as perguntas mais intimistas, deixamos de lado a possibilidade de experimentar o lugar em nome do cronograma apertado. Não podemos sentir a chuva caindo ou ver o pôr do sol. Não podemos ver as estrelas brilhando no céu. Não sabemos que gosto tem aquela frutinha vermelha que colore a paisagem. Não sabemos do efeito dos sons dentro e fora do Abrigo tampouco sabemos qual é o cheiro da fumaça de uma fogueira. A liberdade imposta ao grupo foi fator decisivo neste processo. Não havia um coordenador, mas um conselheiro, ou 
como diria Nayara: "um mediador", se é que posso me imputar este papel. Custamos a nos acostumar com a ideia de não termos alguém que determinasse o que deveria ser feito. Ainda segundo Nayara: "Nossa maior dificuldade em campo foi entender o limite desta liberdade". Custamos a nos acostumar a tomar todas as decisões em conjunto. Mas no final foi uma experiência libertadora, pois permitiu a construção de um conhecimento que não vinha de cima para baixo, mas era compartilhado.

\section{Certezas incertas}

Toda esta experiência de campo me trouxe duas grandes certezas.

Em primeiro lugar, creio que construir um conhecimento sobre o passado seja algo mais que apenas abrir sondagens, desenhar perfis estratigráficos e produzir intermináveis listas de material arqueológico. Creio que construir conhecimento sobre o passado seja algo mais que cumprir a legislação em vigor, que embora se pretenda protetora do patrimônio arqueológico permite sua destruição na medida em que favorece a mecanização da prática arqueológica. Pensar realmente dói como diria Reis (2004) e neste sentido é mais fácil preencher formulários do que criar estruturas interpretativas sobre o passado, mesmo porque a este mercado crescente não interessam ilações, interessam apenas números. Neste sentido não podemos simplesmente nos isolar do mundo ao trabalharmos em campo ou laboratório. O mundo material nos cerca e os objetos e sítios com que trabalhamos fazem parte deste mundo. Não creio que a vivência de campo ou de laboratório seja em si a resposta para tudo, claro que não, mas sem dúvida tais práticas abrem espaço para novas ilações, novas perguntas. Como defende Fahlander (2004), precisamos de um elemento mais criativo em nossas construções científicas, em nossos modelos. Precisamos utilizar fantasias, ficções a fim de expandir nossas estruturas de referência além dos modelos tradicionais. Ao mesmo tempo em que precisamos de novas estruturas narrativas precisamos também descobrir novos meios de extrair informação social da materialidade do passado, pois o registro arqueológico contém mais informação do que costumamos realmente utilizar.

Em segundo lugar, a realidade que nos cerca realmente é duvidosa, se é que existe. Certa vez o mestre taoísta Chuang Tzu sonhou que era uma borboleta, voando aqui e ali. No sonho ele não tinha mais a consciência de sua individualidade como pessoa. Ele era realmente uma borboleta. Repentinamente, ele acordou e descobriu-se deitado ali, uma pessoa novamente. Mas então pensou para si mesmo: "Fui antes um homem que sonhava ser uma borboleta, ou sou agora uma borboleta que sonha ser uma pessoa?" Pensando neste koan zen me pergunto: O que há de real na realidade? Em arqueologia normalmente esquecemos que é a percepção que determina a forma com que os indivíduos veem, interpretam e interferem em seu mundo. Nossas ações são baseadas na percepção que temos do mundo a nossa volta. Não percebemos os objetos no mundo como eles são, mas percebemos através da mediação entre conceitos pré-existentes. Neste sentido, a tão proclamada ciência objetiva, com seus métodos padronizados, perde o sentido. Ao mesmo tempo esta constatação faz com que tenhamos que procurar novos meios para tentar adentrar no passado, pois como dissemos acima, nossa ciência é absolutamente visual. Sei que nos despir de nosso aparato sensorial e de nossa visão de mundo é impossivel, mas temos que considerar que talvez estejamos fazendo ciência da maneira errada.

Acredito que devamos libertar mais vezes nossa imaginação. Não há como perceber, existir e transcender sem imaginar. Devemos possibilitar que nosso senso de reflexão permita a construção e a aplicação de metodologias que busquem escavar pessoas, emoções, ideias e pensamentos e não apenas objetos. Como diria Lorde Tennyson: Venham amigos. Não é tarde para procurar um mundo mais novo. Minha meta é navegar além do pôr-do-sol. Embora não tenhamos a força de antigamente que movia céu e terra, o que nós somos, nós somos. Uma boa indole e corações heroicos, enfraquecidos pelo tempo, mas fortes na vontade de lutar, procurar, encontrar, e não hesitar (Barbosa 2000). Se criamos a realidade que nos cerca, talvez esteja na hora de recriar a arqueologia que praticamos. 
PELLINI, J.R. Neither better, nor worse, just a different excavation. R. Museu Arq.

Etn., São Paulo, n. 21, p. 3-15, 2011.

Abstract: The recent critics of the methodology of excavation, have emphasized its hierarchical nature and the persistence of objective methods of data collection. Although the current excavation techniques produce invaluable information and material on the site, they say nothing about the past itself. In this sense we need a more reflective, creative and intimist fieldwork and not just a passive record of evidence. In this context was excavated the rockshelter Cambaiúvas at Unai city in the Minas Gerais Estate, by a team of IGPA/PUCGO under the coordination of Dr. José Roberto Pellini.

Keywords: Archaeological Theory - Fieldwork practice -Pós-Processualism.

\section{Referências bibliográficas}

\section{ANDREWS, J.; BARRETT, J.; LEWIS, J.}

2000 Interpretation not record. The practice of archaeology. Antiquity, 74: 525-30.

BARBOSA, F.

2000 Cinco Séculos de Poesia. São Paulo: Lanzy.

BENDER, B.

1998 Stonehenge. Making space. Oxford: Berg.

BERGGREN, A.; HODDER, I.

2003 Social practice, method, and some problems of field archaeology. American Antiquity, 68 (3): 421-34.

BORGES, D.

1987 Rio Araguaia. Corpo e Alma. São Paulo: IBRASA.

BRADLEY, R.

2006 Bridging The Two Cultures. Commercial Archaeology and The Study of Prehistoric Britain. The Antiquaries Journal, 86: 1-13.

2003 Seeing things: perception, experience and the constraints of excavation. Journal of Social Archaeology, 3 (2): 151-168.

CHADWICK, A.

2010 What Have The Post-processualists Ever Done For Us? Towards An Integration of Theory and Pratice and Radical Field Archaeologies. In: http://independent. CLASSEN, C. academia.edu/AdrianChadwick/Papers

1993 Worlds of sense. New York: Routledge.

1997 Foundations for an anthropology of the senses. International Social Science Journal, 153: 401-20.
CUMMINGS, V.

2002 Experiencing texture and transformation in the British Neolithic. Oxford Journal of Archaeology, 21 (3): 249-261.

DUBORD, G.

1995 The society of the spectacle. New York: Zone Books.

EDGEWORTH, M.

1992 Analogy as Practical Reason. The Perception of Objects in Archaeological Practice. The Quarterly Newsletter of the Laboratory of Comparative Human Cognition, 14 (1): 1-8.

2003 Acts of Discovery. An Ethnography of Archaeological Practice. BAR International Series 1131. Oxford, Archaeopress.

FAHLANDER, F.

2004 Archaeology and Anthropology: Brothers in Arms? On Analogies in 21st Century Archaeology. In: Fahlander, F; Oestigaard, T. (Eds.) Material Culture and Other Things. Post-disciplinary Studies in the 21st Century. Gothenburg, University of Gothenbug: 185-212.

HAMILTON, S.; BENDER, B.; TILLEY, C.

2006 Stone Worlds. Narrative and Reflexivity in Landscape Archaeology. London: University College.

HODDER, I.

2000 Towards reflexive method in archaeology. The example of Çatalhoyuk. Cambridge: Cambridge University Press.

1999 The archaeological process. An introduction. Oxford: Blackwell. 
HOWES, D.

1991 The varieties of sensory experience: A sourcebook in the anthropology of the senses. Toronto: University of Toronto Press..

2006 Charting the sensorial revolution. Senses and Society, 1(1): 113-128.

LUCAS, G.

2001 Critical approaches to fieldwork. London: Routledge.

MASINI, E.

1991 Enfoque fenomenológico de pesquisa em educação. In: Fazenda, I. (Org.) Metodologia da pesquisa educacional. 2. ed. São Paulo: Cortez.

QUINTANILHA, M.

1979 Na Volta da Esquina. Editora Globo. Rio de Janeiro.

REIS, A.

2004 Não Pensa Muito que Dói. Um Palimpsesto sobre Teoria na Arqueologia Brasileira. Tese de Doutoramento. Universidade Estadual de Campinas.

SHANKS, M.; HODDER,I.

1995 Processual, postprocessual and interpretative archaeologies. In: Hodder, I.; Shanks, M.; Alexandri, A.; Buchli, V.; Carman, J.; Last, J.; Lucas, G. (Eds.) Interpreting archa- eology. Finding meaning in the past. London, Routledge: 34-44.

SHANKS, M.; TILLEY, C.

1987 Re-Constructing Archaeology. Theory and Practice. NewYork: Routledge.

TILLEY, C. (Ed.)

1990 Reading Material Culture. Structuralism, Hermeneutics and Post-Sructuralism. Oxford: Basil Blackwell.

TILLEY, C.

1997 A Phenomenology of Landscape. Places, Paths and Monuments. Oxford: Berg.

2004 The materiality of stone. Explorations in landscape phenomenology. Oxford: Berg.

TRIGHAM, R.

1994 Engendered Places in Prehistory. Gender, Place, and Culture, I (2): 169-203.

1991 Households with Faces: the challenge of gender in prehistoric architectural Remains. In: Gero, J.; Conkey, M. (Ed.) Engendering Archaeology: Women and Prehistory. Oxford, Basil Blackwell: 93-131.

WHITMORE, C.

2005 Multiple Fields Approaches in the Mediterranean: Revisiting The Argolid Exploration Project. In: HTTP:metamedia.stanford. edu. 